\title{
Los márgenes del discurso. Voces y silencios en La máquina de escribir (1996), de Juan Martini
}

\section{Liliana Tozzi*}

Resumen: En La máquina de escribir (1996) de Juan Martini se presenta un discurso fragmentado, que reproduce el tono y el ritmo de las conversaciones en el ámbito de un bar. La proliferación de voces inscribe en el texto parte de los discursos sociales del siglo XX y da cuenta de las tensiones sociales que se generan, especialmente a partir de las políticas neoliberales de los años noventa en Argentina. En este trabajo me propongo analizar, desde un enfoque sociocrítico, algunos de los modos en los que ingresa la dimensión social en la novela: la revisión del pasado, la circulación del poder y la visión crítica de la realidad social y económica de finales del siglo XX.

PalabRAS Clave: Juan Martini, La máquina de escribir, Literatura argentina, Discurso social.

ABSTRACT: La máquina de escribir (1996) of Juan Martini presents a fragmented discourse, which reproduces the tone and the rhythm of the conversations in the area of a bar. The proliferation of voices inscribes in the text the social speeches of the 20th century and the social tensions that are generated, specially from the neoliberal policies of the nineties in Argentina. In this work I propose to analyze, from a sociocritic approach, some manners in which we can read the social dimension in the text: the review of the past, the configuration of the power and the critical vision of the social and economic reality of ends of the 20th century.

Key words: Juan Martini, La máquina de escribir, Argentinian Literature, Social discourse.

Facultad de Lenguas, Universidad Nacional de Córdoba, Argentina (tozzi_liliana@fibertel. com.ar). 


\section{INTRODUCCIÓN}

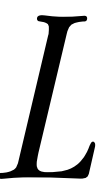

a máquina de escribir (1996) ${ }^{1}$ de Juan Martini construye una historia a partir de un discurso fragmentado que reproduce, en su formulación, el tono y el ritmo de las conversaciones en el espacio de un bar. La proliferación de las voces inscribe de diversas maneras - reproduce, cuestiona, modifica-las manifestaciones ideológicas que circulan en la red del discurso social de Argentina en el siglo xx; específicamente, las tensiones políticas y sociales que genera el sistema neoliberal y su inserción conflictiva en el marco de la política global.

En este trabajo, me propongo analizar algunos de los modos en los que ingresa la dimensión social en el texto: 1) la utilización particular del folletín, que permite leer, desde el presente, algunos fragmentos de la historia pasada; 2) el discurso sexual que refracta la represión política a través de diversas maneras de imposición del poder; y 3) la configuración de los grupos sociales, que reformula en la ficción los abusos por parte de los grupos económicos y políticos hegemónicos. Intentaremos analizar estos aspectos desde una perspectiva metodológica que considera el texto literario en una sincronía, ${ }^{2}$ es decir, no como una producción transhistórica sino inmersa en la economía discursiva de su contexto social. En este sentido, nuestro enfoque teórico-metodológico se ubica dentro del marco de la sociocrítica, que considera el discurso literario como el lugar donde se entrecruzan, a través de una serie de mediaciones, diversas representaciones de lo social:

La sociocrítica [... ] postula que la realidad referencial sufre un proceso de transformación semántica por efecto de la escritura, que codifica este referente en forma de elementos estructurales y formales, lo cual supone que se reconstruya el conjunto de mediaciones que desconstruyen, desplazan, re-organizan y re-semantizan las diferentes representaciones de lo vivido individual y colectivo. [...] dedica más particularmente su atención a los microespacios polifónicos y conflictivos que se descubren en la materia pretextual y textual así como a las modalidades de la inscripción de lo social en el texto. ${ }^{3}$

1 Juan Martini, La máquina de escribir, Buenos Aires, Seix Barral, 1996.

2 Marc Angenot, Interdiscursividades. De hegemonías y disidencias, Córdoba, Universidad Nacional de Córdoba, 1998, p. 81.

3 Edmond Cros, "Sociología de la literatura", en Marc Angenot [coord.], Teoría literaria, México, Siglo xxi Editores, 1993, p. 166. 
La proliferación de voces se inscribe en la multiplicidad de enunciados del discurso social; el texto se configura como novela polifónica en sentido bajtiniano, ${ }^{4}$ que organiza artísticamente la diversidad social del lenguaje y refracta la dimensión histórico-social.

\section{LA MÁQUINA DE NARRAR}

La novela narra la llegada de un escritor a los alrededores fluviales de una gran ciudad, posiblemente en el Tigre, para investigar la historia de Catherine Polignac, una francesa discípula del ingeniero Eiffel. Con la misma tecnología utilizada por el célebre constructor de la torre de París, ella dirige la edificación, a principios del siglo xx, del hotel y el bar donde transcurren las acciones que se narran. Otro personaje clave dentro de la trama de la novela es el escritor llamado Onetti, ${ }^{5}$ quien escribe en una mesa del bar la historia de Catherine en forma de folletín, una contradictoria y ambigua trama policial que surge a partir de las versiones que le ofrecen los asistentes. Un secreto francés, como titula el escritor a la novela por entregas, se publica en la contratapa del diario La Tribuna, cuyas columnas también escribe Onetti desde la mesa del bar de Strauss. Este escenario funciona como recolector de microrrelatos que se superponen y se alternan con un sinfín de anécdotas, a través de las cuales desfila gran parte de la historia del siglo xx. Por otra parte, en el presente del relato, se narran los problemas laborales de un grupo de trabajadores enfrentados con las empresas multinacio-

4 Cfr. Mijaíl Bajtín, Teoría y estética de la novela, Madrid, Taurus, 1991, pp. 77-182.

5 En este personaje puede observarse una referencia al escritor uruguayo Juan Carlos Onetti, que puede leerse como un homenaje a su trayectoria literaria y periodística a través de su labor en las redacciones de periódicos, tanto en Montevideo como en Buenos Aires. Además, se presentan relaciones intertextuales con la obra narrativa del escritor uruguayo, como la imagen del barco que se pudre en la orilla, que el personaje de La máquina de escribir mira reiteradamente a lo largo del relato, que remite a El astillero (1961). A partir de las relaciones intertextuales con la obra de este escritor surgen numerosas líneas de análisis que exceden los límites de este trabajo. Del mismo modo, se presentan muchas otras referencias intertextuales, como la utilización del tema del doble, de extensa tradición en la literatura - como se afirma explícitamente en la novela - que remite, entre otras, a la obra de Jorge Luis Borges. Otra línea de lectura posible se refiere al estado de la literatura argentina a finales del siglo xx. 
nales que construyen una autopista y un shopping de cien mil metros cubiertos; dichas empresas ejercen, a través de sus "servicios de seguridad", la violencia y la represión ilegal sobre los trabajadores que protestan.

La figura del escritor se multiplica a través de varios personajes: Onetti, el Alter Ego, imagen especular del escritor, y Cramer, personaje que asume la voz narrativa mediante un desdoblamiento en narrador omnisciente, en tercera y en primera persona. Además, cuando Onetti se marcha, Gretel, redactora de $L a$ Vanguardia, el otro periódico del lugar, ocupa su lugar en la mesa del bar, constituyéndose de este modo como otra manifestación de la figura del escritor.

A lo largo de la narración, la reconstrucción de la historia del lugar y de la vida de Catherine Polignac se entrelazan con los comentarios y discusiones de los asistentes al bar. Así, La máquina de escribir conduce al lector a través de numerosos temas que marcan la historia cultural y cotidiana del siglo xx: las noticias y rumores sobre los sucesos del lugar, los vínculos personales, los personajes públicos de la política, el espectáculo y la cultura, la evocación del personaje histórico de Eva Perón, el futbol, el sexo, la política, el cine, la literatura.

\section{LA (RE)CONSTRUCCIÓN DEL PASADO: LA "LITERATURA CIENTÍfICA” Y EL FOLLETÍN}

El escritor, llamado Onetti, llega al bar de Strauss, se sienta y pide un café y una máquina de escribir. Ute Wolf, la mujer de Strauss, le trae una Lexikon 80, "una reliquia", 6 donde Onetti escribirá las columnas de La Tribuna, el periódico local que dirige y en cuya última página publica la historia de Catherine Polignac. La intención del escritor es investigar el caso de la discípula del ingeniero Eiffel para escribir una obra que denomina de "literatura científica" pero que, sin embargo, redacta en forma de folletín, un género considerado menor:

La forma folletinesca emigra entre la novela popular y la novela sentimental, entre la novela de los "nuevos ricos" y la novela de la pobreza, entre la anormalidad y la lo cura, entre el exotismo, la voluptuosidad y la pornografía [ . . ], tratando de absorber 
los recursos temáticos, ciertas estructuras narrativas, e imponiendo un sello de "degradación" de los elementos temáticos y técnicos del relato. ${ }^{8}$

El folletín no se transcribe en el relato, de modo que el lector de La máquina de escribir nunca lo lee; sólo conoce su contenido, sus modos de producción y de recepción a través de los enunciados de los narradores, los cuales se basan, a su vez, en fragmentos de las conversaciones utilizadas como fuente de datos para la "investigación". Las preguntas del escritor operan como disparadores para la proliferación de discursos dóxicos - el chisme, el rumor, el relato oral-que operan entre el recuerdo y la ficción; el pasado se actualiza en el presente: se recuerda y se inventa. Así, se proponen nombres diferentes para la discípula del ingeniero Eiffel - no queda claro si el nombre fue recordado o inventado por los asistentes al bar-, se elaboran diversas hipótesis sobre el desarrollo de los hechos y se exponen opiniones que proponen una lectura actual de los hechos del pasado.

Por otra parte, la historia de la francesa que construye el hotel entreteje algunos elementos temáticos del folletín del siglo xix y principios del siglo xx, como la historia sentimental centrada en el amor-pasión, el deseo y la intriga policial. Sin embargo, las peripecias y las características de los personajes se apartan considerablemente del modelo genérico. El argumento de Un secreto francés podría sintetizarse de la siguiente manera: Juan Manuel Ramos, un estanciero de la zona, contrata, entre 1912 y 1913, a la discípula del ingeniero Eiffel para que construya un hotel, con la moderna tecnología aprendida de su maestro. Catherine Polignac levanta el hotel y, con los materiales que le sobran, construye un bar - que en el presente del relato pertenece a Strauss - para un amigo suyo, con quien mantiene "una compleja relación que deja atrás los límites de la pura amistad". 9 Éste es un joven filósofo alemán, Friedrich Hein, amigo de Martín Heidegger, de quien además se habría enamorado al conocerlo en las duchas de la universidad de Friburgo. El carácter melancólico de Hein se acentúa cuando su amiga-amante, Catherine, "se

8 Nicolás Rosa, "El folletín: historial clínico", en Nicolás Rosa [dir.], Moral y enfermedad. Un sociograma de época (1890-1916), Rosario, Laborde Editor, 2004, p. 14.

9 Martini, op. cit., p. 54. 
pierde en la llanura"10 con la única hija de un hacendado, "una pizpireta de los alrededores"11 de quien también está enamorado Adolfito Ramos, el hijo del dueño del hotel.

El final de la historia, a partir del momento en que las mujeres huyen del lugar, constituye el misterio que se va develando gracias a las investigaciones del escritor y del Alter Ego: encuentran un casco de estancia abandonado donde habrían vivido las dos mujeres en compañía del viejo granjero que cuida del lugar quien, siendo apenas un jovencito, habría mantenido con ellas un vínculo laboral y sexual. Respecto a la muerte de Dominica Krieger, la amante de Catherine, se tejen varias hipótesis relacionadas con la existencia de una carta que no habría llegado a destino. El Buick, una mujer hermosa e impecable con el automóvil de donde se toma su sobrenombre, heredera del hotel, se enamora del escritor y le permite leer "la carta robada"12 donde Adolfito Ramos, presa de los celos, amenaza de muerte a Catherine. El ladrón de la carta es Friedrich Hein, quien impide de este modo que Dominica la lea. El escritor Strauss, ${ }^{13}$ hermano del dueño del bar, desde su residencia en Alemania y a partir de los datos que le envía su hermano, deduce que Dominica Krieger se suicida. Onetti, en cambio, considera que es asesinada por Friedrich Hein. Para su conclusión, acepta como

${ }^{10}$ Ibid., p. 40.

11 Ibid., p. 55.

12 El episodio de "la carta robada" permite establecer relaciones con el relato de Edgar Allan Poe, "La carta robada", en Los crímenes de la Rue Morgue. El misterio de María Rodget. La carta robada y otras narraciones extraordinarias, Buenos Aires, Ediciones Orbis S. A./Hyspamérica, 1983, pp. 62-80 y con El Seminario de Jacques Lacan donde analiza dicho relato y la función de las "cartas", Jacques Lacan, "La carta robada", en El Seminario. Libro 2. El yo en la teoría de Freud y en la técnica psicoanalítica 1954-1955, Buenos Aires, Paidós, 1995, pp. 287-307. En La máquina de escribir, además de la carta robada por Adolfito Ramos aparecen otras cartas. Por ejemplo, algunas que el Buick conserva en el Museo de la obra del hotel; otras que el escritor Strauss envía desde Alemania a su hermano y en las cuales, a través del análisis del estado de la "literatura alemana", se presenta una crítica a la literatura argentina contemporánea. Podría resultar interesante realizar un análisis detallado de la utilización del género epistolar en la novela, puesto que constituye un eje importante en su composición, sin embargo, excede los límites de este trabajo.

${ }^{13}$ El personaje del escritor Strauss remite al novelista Botho Strauss, autor de la novela El hombre joven, entre otras. 
prueba, además de la "carta robada", una "carta falsa", donde Friedrich Hein imita la caligrafía de Adolfito Ramos y amenaza en su nombre a Dominica.

La trama reúne elementos del melodrama y lo policial, pero en algunos aspectos la historia narrada se aparta de las características propias del género. En el plano de lo sexual, por ejemplo, se presentan vínculos que se oponen al precepto de la heterosexualidad obligatoria: la protagonista produce una ruptura con el perfil de los personajes femeninos del folletín tradicional, donde la mujer se caracteriza por la sumisión a los mandatos institucionales del sistema patriarcal y purga con una vida miserable o con el suicidio la culpa por haber transgredido esas disposiciones. ${ }^{14}$ Por el contrario, Catherine Polignac no se subordina a estas normas ni asume ningún castigo por ello: es ingeniera, bisexual y, según una especie de epílogo que ofrece el narrador, toma venganza asesinando en París al que cree autor de la muerte de su amiga, Adolfito Ramos.

Por otra parte, el "maniqueísmo moral [... que preside la ideología del folletín"15 deja paso, en la historia de Un secreto francés, a una visión que rompe con todo tipo de binarismos. La evaluación "moral" se encuentra ausente del relato y surge, en cambio, a partir de los comentarios de los asistentes al bar, cuyas opiniones inscriben los discursos que circulan en la doxa. Las mujeres "no quieren saber nada de la historia de Catherine" porque, según el narrador, las pone "frente al reverso de sus vidas". ${ }^{16}$ En el caso de los hombres, por el contrario, la historia de Catherine se incorpora al imaginario masculino, como extravagancia o anormalidad, integrándose al discurso sexual:

En cambio los puntos no se sienten heridos: es un relato del pasado, una extravagancia o una anormalidad, que es de lo que siempre hablan los puntos - $\mathrm{O} \mathrm{O}$ no?: Pijas colosales, culos históricos, bolas de acero, tetas como melones-, y encima capaz que le encuentran a la historia su perfil ardiente: los puntos, en general, se copan con una fiesta entre minas $[. ..]{ }^{17}$

${ }^{14}$ Una lectura desde la perspectiva de los estudios de género puede resultar esclarecedora para analizar este aspecto y otros relacionados con la construcción de lo femenino y lo masculino, y las rupturas y desplazamientos que se establecen respecto del sistema patriarcal.

15 Rosa, op. cit., p. 24.

16 Martini, op. cit., p. 44.

${ }^{17}$ Loc. cit. 
La noción de anormalidad, que pone en circulación el discurso machista, se contrapone a la naturalidad con que se presentan las formas alternativas de la sexualidad a través de los discursos de otros personajes, como la hermana de Strauss, quien afirma que ama a su sobrina y desea "[ .. . ] verla crecer, abandonar la casa de su padre, entregarse al hombre o la mujer de quien se enamore [.. . $"{ }^{18}$ Otro ejemplo lo constituye el microrrelato de Cramer sobre la historia de Tatín y las dos Florencias, una intriga amorosa en la cual la novia de Tatín -Florencia - lo engaña con otra mujer - también llamada Florencia-; finalmente, él se casa con la novia abandonada por la amante de su ex novia - Maleva - quien a su vez le consigue amantes con las cuales también ella tiene relaciones.

Sin embargo, no hay que perder de vista que el folletín, en este caso, se inserta dentro de la trama de la novela, por lo tanto, las condiciones de producción varían sustancialmente. Dentro de la construcción novelesca, la utilización del género remite al problema de la construcción de un relato, presente en gran parte de la narrativa de Juan Martini. ${ }^{19}$ La historia se arma "en los silencios", "en el error", a través de "hipótesis", cuyos modos de comprobación constituyen más dudas e interrogantes que medios de verificación. La investigación del escritor pivotea entre la "literatura científica" que trabaja sobre "las huellas de la historia" y los relatos que circulan en el espacio del bar, en cuyas fisuras se encuentran "las pistas" para conocer los hechos: ${ }^{20}$

La historia se escribe en los silencios: es palpable: se habla de Catherine Curie, o Polignac, o lo que sea, durante días enteros [...] pero nadie dice una palabra de la

${ }_{18}$ Ibid., p. 72, cursivas nuestras.

19 En La vida entera (1981), la pregunta que atraviesa el relato - ¿Qué historia es ésta?" - articula los distintos planos en que se compone la historia. En novelas posteriores del autor -Composición de lugar (1984), El fantasma imperfecto (1986), La construcción del béroe (1989), El enigma de la realidad (1992), El autor intelectual (2000), Puerto Apache (2002), Colonia (2004) - esta pregunta aparece reformulada, de diversas maneras, como uno de los ejes que construyen la narración. En la novela que nos ocupa, la problematización acerca de los modos de armar una historia se plantea también a través de las interpretaciones sobre la película $\mathrm{Ca}$ sablanca y las reflexiones explícitas del narrador sobre los modos en que "con los mismos materiales" pueden construirse múltiples relatos.

20 Todas las citas de ese párrafo en Martini, op. cit., p. 44. 
otra, de la hija del hacendado de quien se enamora Catherine y con quien se va a vivir al campo, a la llanura, al casco de una estancia ya por entonces, parece, abandonado. Nadie dice nada sobre la amante de Catherine, ni siquiera los puntos, al principio. De modo que aquí hay algo sospechoso, una pista, no se sabe, algo. ${ }^{21}$

A partir de esa grieta que se abre en la superficie de los relatos, se instala el misterio que la investigación intenta develar: "Un secreto francés, digo yo, el folletín que escribe el tipo para la contratapa de La Tribuna, tiene el éxito que tiene porque no se sabe cómo termina [...]" ${ }^{22}$ A la forma cerrada del folletín se contrapone, en este caso, el final abierto que instala el narrador al plantear las dos soluciones posibles: una que descubre Onetti y escribe en el periódico y otra que propone el escritor Strauss, a partir de los datos que le envía su hermana. ${ }^{23}$

La elección del folletín se vincula también con la configuración de lo social y la función de la escritura. Onetti, y posteriormente también el Alter Ego y Cramer, se proponen una obra de "literatura científica" pero escriben un periódico y, dentro de él, un folletín. Estos géneros les permiten la inclusión de la problemática social a través de un discurso para un sector más amplio de lectores, en especial, para los lectores populares, quienes son los más afectados por el sistema económico y social dominante. A diferencia del folletín clásico, donde "la retórica no puede subvertir el orden social, lo confirma y lo legitima", ${ }^{24}$ en Un secreto francés se subvierten las normas convencionales para ofrecer una mirada al sesgo que quiebra el discurso hegemónico.

${ }^{21}$ Ibid., pp. 44 y 45.

22 Ibid., p. 279.

${ }^{23}$ La figura del escritor Strauss, hermano del dueño del bar, que envía cartas donde polemiza sobre la literatura, el desarrollo de la trama del folletín y otros temas que circulan en el bar, plantea de manera sesgada una visión crítica de la literatura argentina de la década del noventa, el papel de los "intelectuales" y la "joven literatura".

${ }^{24}$ Rosa, op. cit., p. 38. 


\section{CARTOGRAFÍA DE LOS MÁRGENES: PODERES Y RESISTENCIAS}

La historia de Catherine Polignac actualiza una etapa de la Historia argentina, ${ }^{25}$ de principios del siglo xx, marcada por la influencia y el prestigio que tiene lo extranjero - y en particular lo francés- para las clases altas. Así, Juan Manuel Ramos manda construir el hotel con las características arquitectónicas utilizadas por el ingeniero Eiffel en Francia, y también importa de Francia el mobiliario:

[...] Catherine Polignac construye el Hotel con tecnología Eiffel- [...] y le agrega cristales, desde luego, como lo indica la época, y un vitraux por aquí y otro por allá, un poco de boiserie, platería, alpaca, terciopelo y otras sedas, tapices, la caoba, el roble y el cedro [...] para abreviar, traído todo, como corresponde, de Europa y de Oriente, porque el dueño del Hotel es un nativo, pero un nativo ilustrado $[\ldots] \cdot{ }^{26}$

La expresión "nativo ilustrado" inscribe en la textualidad una posición ideológica del contexto de principios de siglo. La conjunción adversativa "pero" marca la oposición entre "nativo" e "ilustrado", y genera dos núcleos semánticos que registran de manera particular la dicotomía barbarie/civilización, donde el segundo término remite a la cultura europea.

La historia del hotel marca las etapas de su apogeo y su decadencia:

1) la construcción, con tecnología francesa, "una inversión acorde con los tiempos, con el nacimiento de una nación"; ${ }^{27}$

2) los "tambaleantes" manejos de Adolfito Ramos;

3) la deriva de una "administración involuntaria" caracterizada por la desorientación en ausencia de sus dueños;

4) la época de bonanza de la administración de la abuela del Buick;

5) el "oscuro tiempo" de la nacionalización durante la presidencia de Perón;

6) el presente, con la dirección del gerente Acevedo.

25 Denominamos "historia" con minúsculas a la sucesión de hechos narrados en la ficción; reservamos el término con mayúscula - "Historia"- para referirnos a los hechos que ocurren en la dimensión histórica extratextual.

${ }_{26}$ Martini, op. cit., p. 52.

${ }^{27}$ Loc. cit. 
La historia del hotel reformula, en lo micro, un periodo de la Historia del país. En el presente del relato, los huéspedes son empresarios y ejecutivos de grandes empresas internacionales, que "talan árboles" para construir grandes centros comerciales y autopistas. Los cambios en la cartografía urbana representan las transformaciones en la configuración de la situación social de los habitantes del lugar. Al hablar de la historia de Catherine y su relación con una "pizpireta de los alrededores", el narrador aclara: "denominación, por aquel entonces, no injuriosa, de los alrededores". ${ }^{28}$ Este espacio, con el paso del tiempo, se convierte en el lugar de lo marginal, de la prostitución y del crimen, "donde uno pueda enamorarse de golpe, o donde a uno puedan marcarlo a navajazos para sacarle los 20 o 30 dólares que cuesta por aquí una dosis de heroína". ${ }^{29}$ Allí se construyen los "asentamientos" para los hacheros y obreros que trabajan en la construcción de una autopista y de uno de los shoppings más grandes del mundo. De este modo, el aparente progreso del centro determina un incremento de la pobreza y la marginalidad, que se localiza en los espacios suburbanos, en los bordes. Los conflictos sociales de la ficción dejan ver la situación económica y social de Argentina durante la etapa neoliberal del gobierno de Carlos Menem. ${ }^{30}$

Los hechos narrados se extienden a través de un arco temporal que supera la época en que se escribe la novela: en efecto, desde el presente del relato que se ubica cronológicamente entre 1993 y 1994, el relato se desplaza hacia el pasado -1912-1915 - a través de la historia de Catherine Polignac, y se proyecta

${ }^{28}$ Loc. cit.

${ }^{29}$ Ibid., p. 15.

${ }^{30}$ El programa neoliberal, implementado por el gobierno de Carlos Menem en 1989, se basó en cuatro líneas de ajuste y reforma: "[...] las privatizaciones, la convertibilidad, la reducción del déficit y la apertura económica", en Luis Alberto Romero, Sociedad democrática y política democrática en la Argentina del siglo XX, Buenos Aires, Universidad Nacional de Quilmes, 2004, p. 245. Entre sus principales efectos negativos, se cuenta el desempleo, producto de la caída de empresas locales, los despidos de las estatales privatizadas y la reestructuración de las privadas que siguieron en pie. Por otra parte, como señala Ricardo Sidicaro, "la trama compleja de los intereses de los actores socioeconómicos predominantes conoció un desplazamiento en beneficio de los inversionistas extranjeros, situación que colocó al gobierno ante interlocutores aún con más poder de negociación". Ricardo Sidicaro, La crisis del Estado, Buenos Aires, Eudeba, 2005, p. 45. Múltiples hechos de corrupción acompañaron este proceso. 
hacia el futuro, hasta "la última noche del siglo" (recordemos que la novela se publica en 1996).

Así, el pasado y el futuro se insertan en el presente y se leen desde allí. La historia del lugar se reconstruye a través del relato de Catherine y de los restos que el Buick conserva en el Museo de la Obra del Hotel. El presente se encarna a través del relato de las inversiones económicas y la situación de los obreros, que refleja la situación política de Argentina: la inauguración de la autopista y el shopping, con un acto donde están presentes el presidente, el gobernador de la provincia, empresarios europeos, funcionarios dirigentes de futbol y hasta "un cantante de rock'n roll" y un "corredor alemán de Fórmula 1", ${ }^{31}$ recoge elementos del periodo en que Eduardo Duhalde era gobernador de Buenos Aires, durante la presidencia de Carlos Menem. ${ }^{32}$ De este modo, la ficción registra una valoración crítica de la época. En su artículo "Neoliberalismo y literatura en Argentina [... ]", María Cristina Pons afirma, al referirse a La máquina de escribir:

En esta novela de Juan Martini, si bien se alude, de manera auto-referencial, a una poética que valora la diversidad, la fragmentación, los silencios, las contradicciones y la incertidumbre en una obra literaria, a su vez, se sugiere que estos aspectos no son más que un reflejo especular de la época a la cual se refiere de manera inequívoca. $[\ldots]$.

El sentido de abandono, alienación y aislamiento, y el de haber quedado librado a las circunstancias, son ecos de un país en el que el "sálvese quien pueda" y la fragmentación social estaban a la orden del día. ${ }^{33}$

31 Martini, op. cit., p. 308.

32 Eduardo Duhalde (1941) fue vicepresidente del primer gobierno de Carlos Menem y renunció a su puesto para hacerse cargo de la gobernación de la provincia de Buenos Aires, desde 1991. Fue reelecto para el cargo en las elecciones de diciembre de 1994. Durante su mandato se realizaron numerosas obras públicas, aunque también se incrementó el endeudamiento del estado provincial y se hicieron denuncias de corrupción e ineficacia. Roberto Ortiz de Zárate, "Eduardo Duhalde", Centro de Investigación de Relaciones Internacionales y Desarrollo, septiembre de 2006. En http://www.cidob.org/es/documentacion/biografias_lideres_politicos/america_del_ sur/argentina/eduardo_duhalde\#2.

33 María Cristina Pons, "Neoliberalismo y producción cultural. Neoliberalismo y literatura en Argentina: entre una retórica mercenaria y la autonomía de un arte crítico", en Espéculo. Revista de Estudios Literarios, núm. 41, Universidad Complutense de Madrid, 2009. En www.ucm.es/ info/especulo/ numero41/neolibe2.html. 
La implementación de una nueva economía basada en la minería y en la tala de árboles, unida a los recientes negocios económicos - autopistas, shoppings-, se presenta desde el discurso hegemónico como factores para el crecimiento y el desarrollo; ello determina la emergencia de nuevos grupos de trabajadores, compuestos por obreros argentinos - ex desempleados e inmigrantes, los "rusos"- - En efecto, las ideas de progreso presentadas por la ideología del discurso "oficial" son desmontadas por el discurso del narrador:

[...] estos emprendimientos, sostienen esferas oficiales, son de vital importancia porque representan el empleo de mano de obra desocupada, por un lado, y la realización de una autopista que unirá la urbe con un moderno centro comercial de cien mil metros cubiertos, inversión que representará por efecto de la competencia una caída general de los precios, cierre de pequeños centros comerciales, despidos masivos de trabajadores, creación, es claro, de mano de obra desocupada y, desde luego, más barata para la cual se crearán, a su vez, es el plan, nuevos puestos de trabajo. ${ }^{34}$

La idea de progreso a través de las inversiones y la presencia de las empresas multinacionales se desarticula en la obra al dejar al descubierto la marginalización social que implica, puesto que la nueva economía emplea para desemplear y opera así, en realidad, como generadora de mayor desocupación. Por otro lado, la expresión "mano de obra desocupada" actualiza una doble semantización, históricamente situada en la década del noventa: por una parte, el desempleo de las masas de trabajadores ante el avance de la globalización y las políticas neoliberales; por otra, remite a las fuerzas represivas durante la dictadura militar, que al quedar "desocupadas" con el advenimiento de la democracia, se trasladan al ámbito privado de las empresas de seguridad.

En la novela, los "asentamientos" en "los alrededores" dan cuenta de la situación de marginalidad de los grupos de trabajadores, que sufren la explotación de los empresarios internacionales. Muchos de estos asalariados son inmigrantes provenientes de diferentes países pero que se mencionan, en la denominación que circula entre los asistentes al bar, con el adjetivo "rusos". En contraposi-

34 Martini, op. cit., p. 60. 
ción con este grupo social se ubican los empresarios extranjeros, representados por la figura de Benetton como ejemplo de la "nueva economía". El aparente progreso desarrolla una doble práctica: la agresión "ecológica", mediante la cría de ovejas que reemplaza a la tradicional ganadería vacuna de la llanura argentina - "se ne frega altamente en las tradiciones ganaderas del lugar",$-{ }^{35}$ y la corrupción en los "arreglos" ilegales mediante la financiación de clubes de futbol.

El ejercicio del poder a través de la represión y la violencia determina una tensión social que genera prácticas de resistencia por parte de los trabajadores. La situación se denuncia en La Tribuna, el periódico que dirige Onetti, y con mayor vehemencia en La Vanguardia, la publicación que inaugura Gretel. ${ }^{36}$ Estos medios representan dos propuestas alternativas al discurso oficial: la primera, dentro de una tendencia social-demócrata, "populista", según la calificación despectiva de Gretel; la segunda, a través de un socialismo militante que levanta las banderas del Che Guevara y la Revolución cubana. Ante la violencia que se desencadena: "Gretel, disuelta en lágrimas, escribe, no puede parar de escribir el editorial de La Vanguardia [...] En el bar, el tipo, con el ojo seco, la boca torcida, los surcos de la consternación hundidos en el rostro, hace lo mismo: escribe, denuncia la atrocidad, el poder sin límites, la violencia canalla" ${ }^{37}$

Un ejemplo de la violencia represiva lo constituye la golpiza que la Merca ${ }^{38}$ y su grupo le propinan al Pardito, el adolescente hijo del dueño del almacén de ramos generales. Las prácticas de explotación se entrecruzan con la corrupción y con la imposición del poder a través de la violencia sobre los cuerpos:

35 Ibid., p. 141.

36 Otra posibilidad de análisis, que dejamos pendiente porque excedería los límites de este trabajo, sería el estudio de la configuración del poder mediante la articulación con las teorías de Foucault. Cfr. Michel Foucault, Historia de la sexualidad. 1. La voluntad de saber, trad. de Ulises Guiñazú, Buenos Aires, Siglo xxi Editores, 2002 y Microfísica del poder, $3^{\mathrm{a}}$ ed., Madrid, Las Ediciones de La Piqueta, 1992.

37 Martini, op. cit., pp. 155 y 156.

${ }^{38}$ La Merca es uno de los integrantes de los grupos que lleva a cabo las tareas de represión entre los trabajadores. Este término, en el argot de los sectores marginales y de los traficantes y consumidores de drogas, alude a la cocaína. En el relato, este personaje consume habitualmente esta droga, al igual que todos los personajes que lo rodean cotidianamente. Otro término relacionado con este campo semántico que se utiliza en el texto es el verbo "esnifar" por "aspirar". 
[...] los tipos armados por la Merca, Luque, Dalton, caen de noche en los albergues, las casillas, las carpas, la intemperie donde duermen no pocos, propinan escarmientos feroces, purgas, dicen, nadie sabe por qué, pero se los llama escarmientos, o purgas, por eso en los alrededores, poco a poco, surge una clase de sujetos que negocia cosas, más camas, por ejemplo, raciones regulares de azúcar [...]. A estos sujetos pronto se les llama, es claro, la Nomenklatura. Lo que tiene de bueno la política es esto, establece las cosas, produce las reglas, le da a la vida ciudadana un ordenamiento $[\ldots] .^{39}$

La utilización de la ironía en el discurso del narrador desarticula los enunciados del discurso oficial. El orden impuesto por los "grupos de tareas", y apoyado por "la nomenklatura" (una agrupación de origen sindical que opera como refuerzo del poder político hegemónico) es en realidad el desorden de la corrupción, del abuso de poder, de la violencia. Estos grupos remiten a la "mano de obra desocupada" de la etapa del proceso militar. En el plano de la historia narrada, el fascismo que caracteriza el manejo de las relaciones entre los contratistas y los obreros en los negocios comerciales de la zona podría considerarse como metonimia del sistema político.

Es de alguna manera una situación paralela a la que se plantea en La vida entera (1981), novela anterior del autor, pero mientras en esta novela el ejercicio del poder aparece individualizado a través del personaje del Alacrán —el caudillo del lugar-y de quienes lo suceden en el poder - el Oriental, Encarnación, la Rusita-, en La máquina de escribir el centro se caracteriza por la despersonalización, característica del mundo globalizado de los noventa. En relación con la dimensión histórica, la represión y el cercenamiento de las libertades individuales y de la libertad de expresión ya no corren por cuenta del gobierno, como sucedía en la etapa de la dictadura, sino que ahora está en manos de "las compañías de Seguridad", organismos que operan desde el ámbito privado, pero protegidos y legitimados por las autoridades democráticas.

Las prácticas abusivas se vinculan con las prácticas sexuales de los represores, entre los cuales se destaca el personaje de la Merca, cuyo lenguaje -e incluso su sobrenombre-incorpora la jerga marginal del mundo de la droga, así

39 Martini, op. cit., p. 227. 
también como un discurso sexual que repone una visión machista, lugar de articulación con prácticas propias del fascismo:

[...] chasqueás los dedos, ¿ves?, así [...] y se te ponen entre las piernas, abren la boca, se meten la pija, te la chupan. No lloran, no se quejan, no hablan, no dicen nada, las minas bien enseñadas: [...] y de vez en cuando, para mantenerlas en forma, para que no se distraigan, cuando menos se lo esperan, izas!, una piña, un correazo, una patada en las costillas, vas a ver, se recuperan, se te acercan [...] es así, traéme a una de esas pendejas de Benetton y yo te voy a mostrar cómo hay que hacer. ${ }^{40}$

La voz del narrador incorpora el discurso de este personaje y sus acompañantes cuando describe sus prácticas, por ejemplo, utilizar el término "snifa" para aludir a la práctica de aspirar cocaína, a través de un procedimiento recurrente en el texto, por medio del cual el narrador se apropia del discurso de los personajes. Las teorías y las prácticas de la Merca articulan lo sexual con lo político, a través de la violencia legitimada desde lo institucional, que establece una línea de continuidad con los abusos cometidos durante la dictadura militar. Las alusiones a este periodo aparecen a través de la referencia a la tortura, como el "oficio en memoria de un ex torturador" que cubre el periodista José María López; también en la mención a los "comunicados" de las compañías de seguridad y a las expresiones que utilizan los represores durante las "purgas", procedimientos que incluyen violaciones, maltrato físico a hombres, mujeres y niños e incluso la muerte de algunos obreros: ${ }^{41}$

El resultado de la última purga pactada entre la Nomenklatura y la Merca arroja, además de los heridos, el saldo de dos muertes: Ramiz Hoxha y el Garabato caen acribillados a balazos cerca de la mesa donde Dalton viola a la mujer de un peón que piensa que los trabajadores deben organizarse, desautorizar a la Nomenklatura, elegir democráticamente a sus representantes, etcétera $\backslash$ Infiltrados, dice el

${ }^{40}$ Martini, op. cit., pp. 247 y 248.

41 El término "comunicado" alude a los "Comunicados" que emitía la Junta Militar durante la etapa de la dictadura (1976-1983) en Argentina; las "purgas" remiten a las prácticas represivas en masa que se realizaban contra quienes se consideraban opositores al régimen. 
comunicado sumarios de una de las compañías de seguridad contratadas por las empresas constructoras en cuya nómina figuran la Merca, Luque, Dalton, agitadores profesionales, izquierdistas trasnochados son los responsables de la provocación que termina con este balance luctuoso $[\ldots]^{42}$

Poco después de la medianoche nos enteramos de que mueren dos hacheros y el Nene Menéndez [... ] la Merca en persona, me dicen, los fusila. ${ }^{43}$

La resistencia se produce a través del discurso — se afirma que la Merca "se coje a las minas" pero "le gusta que le rompan el culo"- ${ }^{44} \mathrm{y}$ de los hechos, puesto que es asesinado con la misma ferocidad que él aplica a sus víctimas, a través de un acto que repone algún tipo de justicia. La identidad del vengador permanece indefinida; los rumores señalan, alternativamente, a Onetti, a Cramer, a Hansel y a Gretel; esta indefinición permite que la autoría del crimen se desplace de lo individual a lo colectivo, y se instituya como representación de la resistencia de un conjunto social que ha sido brutalmente sometido. No es casual que en esos días, en La Vanguardia, aparezca la foto de Clara Petacci y Benito Mussolini, colgados "como reses, en la Piazza di Loreto". ${ }^{45}$ Gretel afirma: "A mí no me dice políticamente nada que el fascismo coma mierda, siempre confunde, el fascismo, el cerebro con los huevos". 46

En esta novela, de manera similar con lo que sucede en La vida entera (1981) o en Puerto Apache (2002), Juan Martini elabora historias de marginales y de oprimidos donde la resistencia, de alguna manera, es posible. Pero en la novela de la etapa del exilio del autor estas posibilidades sólo aparecían de manera oblicua a través de la representación simbólica. En La máquina de escribir, en cambio, se presentan reforzadas por una visión utópica, a través del personaje de Lola, la hija del Buick y el escritor, que baila, en la última noche del siglo, con un bula bop en la cintura, mientras se inicia el siglo xxI:

\footnotetext{
42 Martini, op. cit., p. 255.

43 Ibid., p. 270.

${ }^{44}$ Ibid., p. 133.

45 Ibid., p. 298.

46 Ibid., p. 161.
} 
De esta manera llegamos al alba, es el alba, la primera luz de un siglo nuevo, y en ese silencio que se abre sobre lo que se ignora, sobre lo desconocido, lo nuevo, y sobre las cosas de siempre, una niña hace girar en su cintura un aro de luna, [...] la figura de la niña se refleja como un reflejo indisoluble, primordial, en las aguas turbias del río, en los opacos espejos de un amanecer ceniciento como la noche que ha quedado atrás [...] algo que no es pura y simplemente lo que se ve: una niña que en el alba del primer día de un siglo nuevo hace bailar en su cintura un aro de luz $[\ldots]^{47}$

En el último suspiro del siglo el Buick, Margarethe Strauss, el gerente Acevedo, Gretel, yo, alzamos las copas, brindamos, de alguna manera, somos felices. Lola baila junto al río con un aro de plata en la cintura $[\ldots] .^{48}$

La figura de la niña, unida a las expresiones "aro de plata" y "aro de luz", y a los festejos del narrador y los demás personajes, proyecta una imagen positiva, que permite pensar en la posibilidad de nuevas propuestas utópicas.

\section{PARA CONCLUIR}

"La máquina hace lo que quiere. La máquina escribe lo que quiere", ${ }^{49}$ la máquina -una Lexikon 80-, caracterizada reiteradamente como "una verdadera reliquia", "inapreciable en las viejas redacciones periodísticas" ${ }^{50}$ establece el vínculo entre la escritura periodística y la de ficción, que se unen en el periódico y en el folletín que escribe Onetti en la mesa-redacción del bar. Las voces de "la cátedra", de "la parroquia", como las denomina el narrador, multiplican los relatos; así, al discurso monológico del poder se contrapone la polifonía de las voces que instala un caleidoscopio de visiones simultáneas y diferentes sobre la realidad.

En La máquina de escribir la confluencia de las voces traduce, cuestiona, modifica los enunciados y los postulados ideológicos del discurso social. El texto trabaja en los márgenes: de los géneros, de los sujetos sociales, del discurso. La polifonía narrativa a través de la proliferación de voces instala la ambigüedad y

\footnotetext{
47 Ibid., pp. 112 y 113.

${ }^{48}$ Ibid., p. 309.

${ }^{49}$ Ibid., p. 284.

${ }^{50}$ Ibid., p. 29.
} 
la contradicción; estos relatos fragmentarios reflejan la dimensión social mediante la recuperación de la historia pasada y la visión crítica del presente. Las múltiples versiones sobre un mismo hecho, la ambigüedad y los silencios operan como base para la construcción de una narración que, al mismo tiempo que se organiza, vuelve sobre sí misma para cuestionar la naturaleza y los límites del relato mismo.

El folletín, el artículo periodístico, el género epistolar, las conversaciones dentro del ámbito del bar, constituyen los materiales para construir la novela. Así como Catherine construye el bar con los restos del hotel, el narrador edifica un relato con los restos discursivos de "la cátedra". De este modo, por encima del fragmentarismo y la contradicción se afirma la posibilidad de construir una historia otra, que se esboza en los bordes y que postula una versión diferente sobre la realidad; tal vez porque, como afirma Juan Martini,

[... cuando en el escenario de la posmodernidad las ilusiones y las esperanzas políticas parecen muertas y enterradas, los escritores volvemos a descubrir que la literatura -como siempre- será política, o no será. ${ }^{51}$

La máquina escribe con los restos de lo real, con el "oro" y la "roña" que encuentra el escritor en los alrededores; escribe, a partir de los silencios y las contradicciones, un relato que se bifurca y se multiplica, donde a partir de cada "agujero negro" se genera una nueva posibilidad de reescribir la historia.

Recibido: 15 de junio, 2010. Aceptado: 19 de noviembre, 2010.

51 "La máquina de escribir", reseña inédita, 24 de agosto de 1996 (atención del autor), p. 5. 
BibLIOGRAFÍA

Angenot, Marc, Interdiscursividades. De hegemonías y disidencias, Córdoba, Universidad Nacional de Córdoba, 1998.

BajTín, Mijaíl, Teoría y estética de la novela, Madrid, Taurus, 1991.

Cros, Edmond, "Sociología de la literatura", en Marc Angenot [coord.], Teoría literaria, México, Siglo xxi Editores, 1993, pp. 145-171.

De Diego, José Luis, Las novelas de Juan Martini. Una poética del error, La Plata, Ediciones Al margen, 2007.

Foucault, Michel, Historia de la sexualidad. 1. La voluntad de saber, trad. de Ulises Guiñazú, Buenos Aires, Siglo xxi Editores Argentina, 2002. , Microfísica del poder, $3^{\text {a }}$ ed., Madrid, Las Ediciones de La Pi-

queta, 1992.

LACAN, JACQUES, "La carta robada", en El Seminario de Jacques Lacan. Libro 2. El yo en la teoría de Freud y en la técnica psicoanalítica 1954-1955, Buenos Aires, Paidós, 1995, pp. 287-307.

MarTini, Juan, La vida entera, $3^{\text {a }}$ ed., Buenos Aires, Seix Barral, 1997. , El enigma de la realidad, Buenos Aires, Alfaguara, 1992. , La máquina de escribir, Buenos Aires, Seix Barral, 1996. , Puerto Apache, Buenos Aires, Sudamericana, 2002.

ción del autor). , "La máquina de escribir", reseña, 24 de agosto de 1996 (aten-

Onetti, Juan Carlos, El astillero, Buenos Aires, Seix Barral, 2003.

OrTIZ DE ZÁRATE, RoBerTo, "Eduardo Duhalde", Centro de Investigación de Relaciones Internacionales y Desarrollo, septiembre, 2006. En http://www.cidob. org/es/documentacion/biografias_lideres_politicos/america_del_sur/argentina/eduardo_duhalde\#2.

Poe, Edgar Alan, "La carta robada", en Los crímenes de la Rue Morgue. El misterio de María Rodget. La carta robada y otras narraciones extraordinarias, Buenos Aires, Orbis, Hyspamérica, 1983, pp. 62-80.

Pons, María Cristina, "Neoliberalismo y producción cultural. Neoliberalismo y literatura en Argentina: entre una retórica mercenaria y la autonomía de un arte crítico", en Espéculo. Revista de Estudios Literarios, núm. 41, Universi- 
dad Complutense de Madrid, 2009. En www.ucm.es/info/especulo/numero41/neolibe2.html.

Romero, Luis Alberto, Sociedad democrática y política democrática en la Argentina del siglo XX, Buenos Aires, Universidad Nacional de Quilmes, 2004. Rosa, Nicolás, "1. Razones de uso: manuales y disciplinas", en Usos de la literatura, Rosario, Laborde Editor, 2003, pp. 15-26. , "El folletín: historial clínico", en Nicolás Rosa [dir.], Moral y enfermedad. Un sociograma de época (1890-1916), Rosario, Laborde Editor, 2004, pp. 11-46.

SidiCARO, Ricardo, La crisis del Estado, Buenos Aires, Eudeba, 2005. 